\title{
RESEARCH
}

Open Access

\section{Synchronous and metachronous liver metastases in patients with colorectal cancer-towards a clinically relevant definition}

\author{
Jennie Engstrand ${ }^{1 *}$ (D), Cecilia Strömberg ${ }^{2}$, Henrik Nilsson ${ }^{1}$, Jacob Freedman ${ }^{1}$ and Eduard Jonas ${ }^{2,3}$
}

\begin{abstract}
Background: Approximately $25 \%$ of patients with colorectal cancer (CRC) will have liver metastases classified as synchronous or metachronous. There is no consensus on the defining time point for synchronous/metachronous, and the prognostic implications thereof remain unclear. The aim of the study was to assess the prognostic value of differential detection at various defining time points in a population-based patient cohort and conduct a literature review of the topic.
\end{abstract}

Methods: All patients diagnosed with CRC in the counties of Stockholm and Gotland, Sweden, during 2008 were included in the study and followed for 5 years or until death to identify patients diagnosed with liver metastases. Patients with liver metastases were followed from time of diagnosis of liver metastases for at least 5 years or until death. Different time points defining synchronous/metachronous detection, as reported in the literature and identified in a literature search of databases (PubMed, Embase, Cochrane library), were applied to the cohort, and overall survival was calculated using Kaplan-Meier curves and compared with log-rank test. The influence of synchronously or metachronously detected liver metastases on disease-free and overall survival as reported in articles forthcoming from the literature search was also assessed.

Results: Liver metastases were diagnosed in 272/1026 patients with CRC (26.5\%). No statistically significant difference in overall survival for synchronous vs. metachronous detection at any of the defining time points (CRC diagnosis/surgery and 3,6 and 12 months post-diagnosis/surgery) was demonstrated for operated or non-operated patients. In the literature search, 41 publications met the inclusion criteria. No clear pattern emerged regarding the prognostic significance of synchronous vs. metachronous detection.

Conclusion: Synchronous vs. metachronous detection of CRC liver metastases lacks prognostic value. Using primary tumour diagnosis/operation as standardized cut-off point to define synchronous/metachronous detection is semantically correct. In synchronous detection, it defines a clinically relevant group of patients where individualized multimodality treatment protocols will apply.

Keywords: Colorectal cancer, Liver metastases, Synchronous, Metachronous

\footnotetext{
* Correspondence: jennie.engstrand@sll.se

${ }^{1}$ Division of Surgery, Department of Clinical Sciences, Karolinska Institutet,

Danderyd Hospital, 18288 Stockholm, Sweden

Full list of author information is available at the end of the article
}

(c) The Author(s). 2019 Open Access This article is distributed under the terms of the Creative Commons Attribution 4.0 International License (http://creativecommons.org/licenses/by/4.0/), which permits unrestricted use, distribution, and reproduction in any medium, provided you give appropriate credit to the original author(s) and the source, provide a link to the Creative Commons license, and indicate if changes were made. The Creative Commons Public Domain Dedication waiver (http://creativecommons.org/publicdomain/zero/1.0/) applies to the data made available in this article, unless otherwise stated. 


\section{Background}

In the USA as well as in Europe, colorectal cancer (CRC) is the third most common cancer and a leading cause of cancer-related death [1]. Approximately 25\% of patients diagnosed with $\mathrm{CRC}$ will be diagnosed with liver metastases during the course of the disease [2-4]. A large number of clinic-pathologic features of CRC liver metastases (CRCLM), including patient characteristics, pre-operative factors, primary tumour and liver metastases characteristics and operative factors have been assessed as prognostic factors [5, 6]. Synchronous vs. metachronous detection or occurrence of CRCLM as prognostic factor was mainly investigated and reported in surgical case series $[7,8]$. There is, however, no consensus on the definition of synchronous and metachronous as used in the context of CRCLM. The time point of diagnosis of the primary tumour, alternatively the time of operation of the primary tumour and a variation of time intervals related to these time points have been used [3]. An effort to solve this was made by Adam et al. in 2015, where synchronous was defined as liver metastases detected before or at the time of diagnosis of the primary tumour [9]. With current trends and developments in CRC and CRCLM treatment, the detection of liver metastases at the time of diagnosis of the primary tumour has important therapeutic implications, both in terms of surgical strategy and the planning of oncologic treatment [10-13]. In a previously published populationbased cohort of patients with CRC, the time of detection of liver metastases (synchronous vs. metachronous) did not significantly influence survival in a multivariate analysis [4]. In this study, previously used definitions of synchronous vs. metachronous detection of CRCLM are applied on that same patient cohort to assess the prognostic value of detection at the various defining time points in a population-based cohort. To identify previously used definitions for synchronous vs. metachronous detection of CRCLM, a literature search was performed for articles where a time point was specified for synchronous vs. metachronous detection.

\section{Methods}

To assess the potential prognostic impact of detection of liver metastases at various time points used to define synchronous vs. metachronous detection of CRCLM, a population-based patient cohort was used. All patients that were diagnosed with CRC in the Swedish counties of Stockholm and Gotland between 1 January 2008 and 31 December 2008 (total population as of 1 November $2008=2,034,886)$ were identified in the Swedish Colorectal Cancer Registry (SCRCR) and included in the study. The SCRCR is a validated database covering more than 99\% of colon cancers diagnosed in Sweden between 2007 and 2011 [14]. Data regarding metastatic disease is not registered in the SCRCR and in order to identify patients in whom liver metastases were detected, the electronic patient records of all included in the study were reviewed for at least 5 years after time of diagnosis of the primary tumour, or until time of death. The authors reviewed all imaging findings and notifications of intraoperative detection of metastases and documented the occurrence of any metastatic disease. Specifically, the time points for diagnosis of the primary tumour, surgery for the primary tumour, diagnosis of liver metastases and in deceased patients' time of death were documented. A detailed description of the data collection and demographic and clinic-pathological features of all included patients has been published elsewhere [4]. In that paper, a slightly different definition of synchronous vs. metachronous was used with some liver metastases detected after treatment allocation but during neoadjuvant chemotherapy were categorized as synchronous. The overall survival (OS) of patients with synchronously vs. metachronously detected liver metastases was compared for different time points defining synchronous vs. metachronous detection, identified from the literature search as described below. The calculation was performed for the group of patients with liver metastases as a whole, as well as separately for patients undergoing curativeintended liver intervention (resection and/or local ablation) and those treated with palliative intent. OS was estimated from time of diagnosis of liver metastasis to death, last follow-up or censored January 21, 2019.

In order to define previously used time point definitions of synchronous vs. metachronous detection, a literature search was performed for publications between 2005 and 2018 that described definitions of synchronous vs. metachronous detection. The reported prognostic value of the distinction in articles where OS and/or disease-free survival (DFS) were reported was also documented. The PubMed, Embase and the Cochrane library databases were searched, and articles were reviewed following the PRISMA statement guidelines [15]. The following search headings were used: (CRC OR colorectal cancer) AND (liver OR hepatic) AND (metastases OR metastasis OR metastatic) AND (synchronous OR metachronous) AND survival. Articles not written in English, duplicates, conference abstracts, case reports, review articles and articles written before 2005 were excluded. The remaining articles were subjected to a more thorough screening. For inclusion, the studies had to (a) specify a definition of synchronous vs. metachronous detection of CRCLM and (b) assess synchronous vs. metachronous detection as a prognostic factor (as OS and/or DSF). If the same population was used in two different studies, the later study was included. Publications not meeting the inclusion criteria were deemed irrelevant. A reference screening was performed to detect 
possible missed articles. The study was approved by the Regional Ethical Review Board in Stockholm.

\section{Statistical analysis}

Non-normally distributed continuous data are presented as medians (min, max) and categorical data as frequencies (percentage). Survival curves were calculated using Kaplan-Meier estimates, and survivor functions were compared using the log-rank test. The threshold for statistical significance was set to $a<0.05$. Sigmaplot 13 (Systat Software, San Jose, CA 95131, USA) were used for the statistical analyses.

\section{Results}

\section{Survival data from the population-based cohort}

During the study period, a total of 1026 patients were diagnosed with CRC. The median age was 71 years $(31,97)$, $485(47.3 \%)$ were females and $651(65.1 \%)$ had a primary tumour of left-sided origin. At 5-year follow-up, 272 (26.5\%) of subjects $(57.7 \%$ male and $42.3 \%$ female) had been diagnosed with liver metastases of whom 65 (24\%) had undergone liver resection, Table 1 . The cumulative incidence of detection of the liver metastases as related to the time of diagnosis of the primary tumour are depicted in Fig. 1. The number of patients with metastases that were classified as synchronous or metachronous according to the different time points used in the literature, namely the time of primary tumour diagnosis (in non-operated patients) or time of primary tumour surgery (operated patients) and 3, 6 and 12 months after the primary tumour diagnosis/surgery, is shown in Table 2.

The overall survival curves of patients with synchronously and metachronously detected metastases for operated and non-operated patients are shown for the different synchronous vs. metachronous-defining time points (Fig. 2). No statistically significant difference in survival at any of the time points was seen, neither for operated nor for non-operated patients.

\section{Review of existing literature on the topic}

The flow chart presenting the results of the electronic database search is shown in Fig. 3. After exclusion, 39 articles were retained, and 2 articles were added from reference screening. The majority of studies reported patients only operated for CRCLM $(n=34), 6$ included both operated and non-operated patients and 1 study only included patients treated with palliative intent (Table 3). Prognostic results as per time point are summarized in Table 4. There was a considerable variation in the number of subjects included in studies (minimum 40, maximum 1784), and the proportion of patients with synchronous detection of liver metastases varied from 31.3 to $79.7 \%$. The most commonly used defining time point for synchronicity was at primary tumour
Table 1 Patient and tumour characteristics of 272 patients with liver metastases

\begin{tabular}{|c|c|}
\hline & $n=272$ \\
\hline Gender, male/female (\%) & $157 / 115(57.7 / 42.3)$ \\
\hline Age, years (min, max) & $68(31,95)$ \\
\hline \multicolumn{2}{|l|}{ Primary tumour location, $n$ (\%) } \\
\hline Caecum/ascending colon & $64(23.5)$ \\
\hline Transverse colon & $13(4.8)$ \\
\hline Descending/sigmoid colon & $90(33.1)$ \\
\hline Rectum & $95(34.9)$ \\
\hline Multiple primary tumours & $9(3.3)$ \\
\hline Unknown & $1(0.4)$ \\
\hline \multicolumn{2}{|l|}{ Nodal stage of primary, $n$ (\%) } \\
\hline No & $43(15.8)$ \\
\hline N1 & $141(51.8)$ \\
\hline N2 & $37(13.6)$ \\
\hline Unknown & $51(18.8)$ \\
\hline \multicolumn{2}{|l|}{ Tumour stage of primary, $n$ (\%) } \\
\hline T0 & $1(0.4)$ \\
\hline $\mathrm{T} 1$ & $5(1.8)$ \\
\hline $\mathrm{T} 2$ & $7(2.6)$ \\
\hline T3 & $131(48.2)$ \\
\hline $\mathrm{T} 4$ & $96(35.3)$ \\
\hline Unknown & $32(11.7)$ \\
\hline \multicolumn{2}{|l|}{ No. of liver metastases, $n$ (\%) } \\
\hline 1 & $55(20.2)$ \\
\hline $2-5$ & $96(35.3)$ \\
\hline $6-10$ & $34(12.5)$ \\
\hline$\geq 11$ & $87(32.0)$ \\
\hline \multicolumn{2}{|l|}{ No. of involved segments } \\
\hline $1-2$ & $111(40.8)$ \\
\hline $3-4$ & 45 (16.6) \\
\hline $5-6$ & $36(13.2)$ \\
\hline $7-8$ & $80(29.4)$ \\
\hline Size of largest liver metastasis (mm) (min, max) & $26(5,120)$ \\
\hline
\end{tabular}

diagnosis/surgery (18 out of 41 publications). There was a trend in a better OS of metachronous detected metastases with an earlier cut-off with $50 \%$ of studies showing statistically significant differences when using a 0 - or 3month definition, compared to $33 \%$ with a 6 -month definition and $0 \%$ for a 12 -month definition; the majority of the studies concluded a non-significant prognostic value of synchronous vs. metachronous detection.

\section{Discussion}

The present study questions the prognostic impact of the time of liver metastases detection in CRC and also 


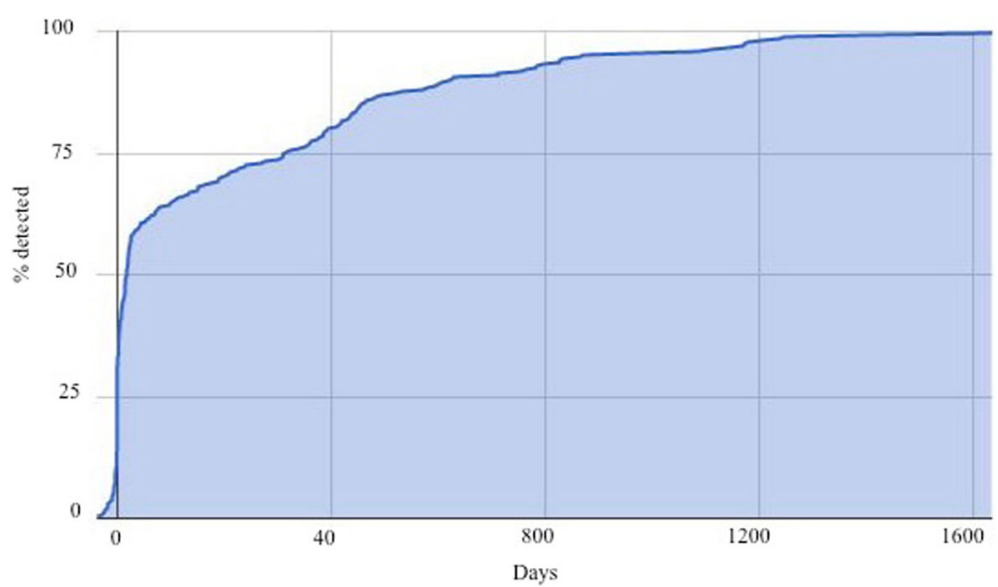

Fig. 1 The time of detection of the liver metastases as related to the time of detection of the primary tumour (non-operated, palliative)/operation for the primary tumour (resected)

the meaningfulness of time points other than the time of primary tumour diagnosis in non-operated patients and time of primary tumour surgery in operated patients as definition of synchronous detection. In a well-defined cohort from a well-defined geographical region in Sweden, no significant difference was seen in survival as measured from time of detection of liver metastases to death between the two groups, irrespective of time points being used.

In patients with CRCLM, the proportions of tumours being detected synchronously and metachronously and the prognostic value of this distinction have been reported in numerous studies [3,9]. Reports addressing the issue differ considerably regarding the time points used as cut-off for defining synchronous vs. metachronous detection. Furthermore, there are wide variations in the number of subjects and the proportions of synchronous vs. metachronous detection in the included cohorts. Although a trend was seen in patients with metachronous detection having a better OS with early time points as cut-off $(50 \%$ of studies showing statistically significant differences using a 0 - or 3-month definition) as opposed to later time points $(50 \%$ for a 6 month and $0 \%$ for a 12 -month definition), there is no compelling evidence that the distinction has any prognostic value. In a study by Furukawa et al., the prognostic value of synchronous vs. metachronous detection was investigated in a cohort of patients with unresectable liver metastases. With the cut-off defined as the time of primary tumour evaluation, no difference in the OS of patients was found [33]. Adam et al. took a consensus approach to the same question and concluded that metachronous tumours are regarded as having a better biology and better survival, and the conclusion was illustrated with survival curves from LiverMetSurvey [9].

With current trends and developments in CRC and CRCLM treatment, establishing the presence of liver metastases at the time of diagnosis of the primary tumour has important therapeutic implications $[6,55]$. Firstly, surgical intervention for the CRCLM needs to be coordinated with the surgery for the primary tumour. Different surgical options, for example the liver first approach or simultaneous resection of primary tumour and liver metastases, need to be considered [10, 56-58]. Secondly, it may also influence the use and timing of oncologic treatment, with neoadjuvant chemotherapy increasingly being favoured in patients with liver metastases detected before surgery of the primary tumour [11-13].

Table 2 The number of patients with liver metastases classified as synchronous vs. metachronous according to the different defining time points.

\begin{tabular}{llllllll}
\hline Time point & \multicolumn{2}{l}{ Synchronous } & & \multicolumn{2}{l}{ Metachronous } \\
\cline { 2 - 3 } & Total & Resected & Non-resected & & Total & Resected & Non-resected \\
\hline Primary tumour diagnosis/surgery & 155 & 26 & 129 & 117 & 39 & 78 \\
Three months post-primary tumour diagnosis/surgery & 174 & 29 & 145 & 98 & 36 & 62 \\
Six months post-primary tumour diagnosis/surgery & 186 & 34 & 152 & 86 & 31 & 55 \\
Twelve months post-primary tumour diagnosis/surgery & 207 & 39 & 168 & 65 & 26 & 39 \\
\hline
\end{tabular}



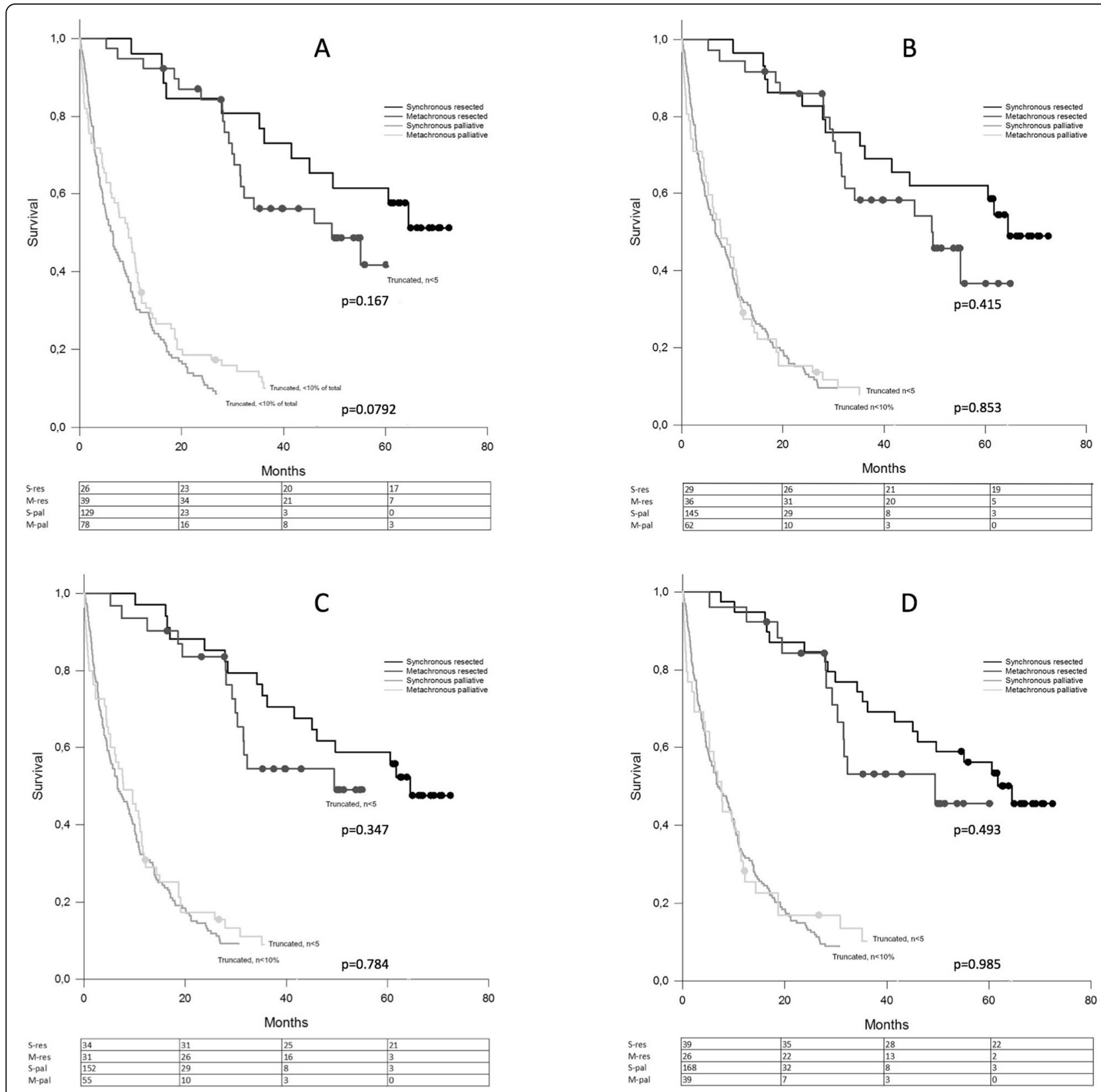

Fig. 2 a-d Overall survival curves for synchronous and metachronous detected metastases. Operated and non-operated patients shown for the different synchronous/metachronous cut-off points at $\mathbf{a}$, detection of the primary tumour (non-operated, palliative)/operation for the primary tumour (resected) and $\mathbf{b}, 3$ months, $\mathbf{c}, 6$ months and $\mathbf{d}, 12$ months after detection/resection of the primary tumour

Terminology frequently used in the literature, for example development of synchronous vs. metachronous metastases, implies two different clinical entities, creating the unfounded impression that the metastatic events occur during the respective periods. The mechanism for CRC metastases to the liver has been described in detail, with tumour cells entering the liver either via the portal vein or hepatic artery, the common point of entry being the sinusoidal space [59]. Whether the risk for new metastases to the liver ceases at removal of the primary tumour is unclear. Patterns of hepatic recurrence observed in a cohort of patients transplanted for CRCLM suggest that previously undiagnosed lung or lymph node metastases could be the source of liver metastases in the transplanted liver $[60,61]$. The development of liver metastases in the transplanted liver in the absence of any 


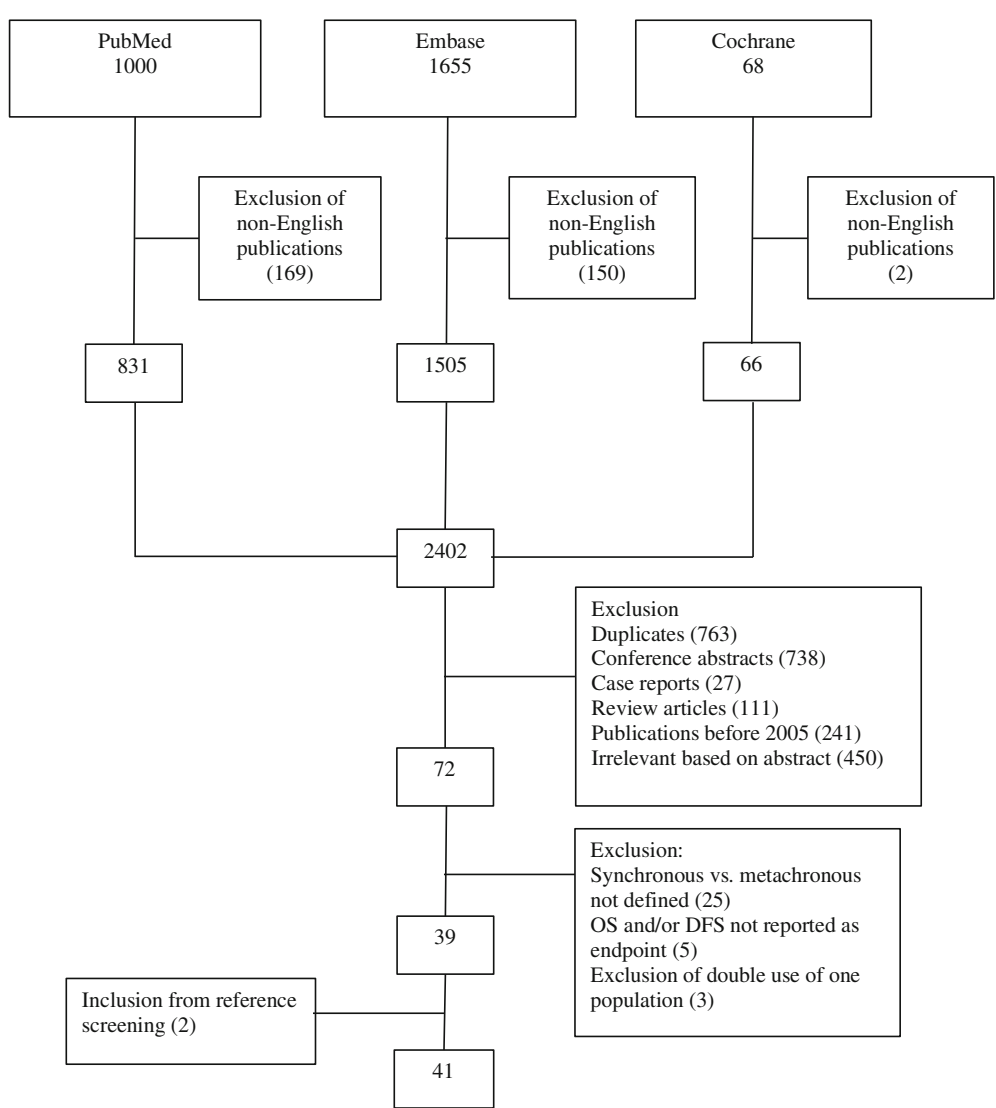

Fig. 3 The flow chart presenting the results of the electronic database search

other metastases suggests that viable tumour cells may persist in the circulation after elimination of the primary tumour and resection of the whole liver with liver metastases. It is however more plausible that preoperatively present but undetected hepatic lesions account for the vast majority of liver metastases detected after operation of the primary tumour. These lesions are therefore potentially detectable at initial liver work-up.

In the light of the above-mentioned, we propose a standardized definition for synchronous vs. metachronous detection of CRCLM that will be rational, semantically correct and will have a clear clinical application, namely the time of operation for the primary tumour in operated patients and the time of diagnosis of the primary tumour, including the metastatic work-up, for patients treated non-operatively for the primary tumour as cut-off. The rationale for having the cut-off for synchronicity during and not before the primary tumour operation is that, even though establishing the presence of metastases during the pre-operative work-up of the primary tumour is optimal in terms of treatment planning, intra-operative detection still to some extent offers the possibility of changing the treatment plan if needed. Intra-operative detection of pre-operatively undiagnosed liver metastases is fortunately an increasingly rare event due to high-quality imaging using high-end technology and state-of-the-art protocols during work-up [62]. The proposed definition will also focus attention on the effectiveness of hepatic imaging at the time of detection of the primary tumour, the proportion of metastases detected before operation for the primary tumour being directly related to the quality and diligence of the imaging strategy. This could serve as a robust parameter of pre-operative imaging quality control. A randomized trial has shown that MRI with liver-specific contrast is superior for detection of CRCLM, as compared to contrast-enhanced CT and MRI with extracellular contrast [63]. Health economic studies suggest that an MRI first approach is from a cost perspective comparable to a step-up approach with contrastenhanced CT first $[64,65]$.

There are, however, a number of limitations that need to be considered in the interpretation and generalization of results. The SCRCR only includes the Swedish population, a relatively homogeneous group in terms of ethnic diversity, and results may not be generalizable. In a previous publication on the total CRC patient cohort from which the CRCLM patients were included in this 
Table 3 Studies comparing the prognostic value of synchronous vs. metachronous detection of CRCLM published in 2005-2018

\begin{tabular}{|c|c|c|c|c|c|c|}
\hline Reference & Year of publication & Cohort & Definition* & Synchronous/metachronous & OS & DFS \\
\hline Mutsaerts et al. [16] & 2005 & Operated & 2 & $43 / 59$ & $S(p=0.048)$ & NR \\
\hline Leporrier et al. [17] & 2006 & All & 3 & $250 / 108$ & NS $(p=0.498)$ & NR \\
\hline Minagawa et al. [18] & 2006 & Operated & 1 & 187/182 & NS $(p=0.19)$ & NR \\
\hline Taniai et al. [19] & 2006 & Operated & 4 & $67 / 41$ & NS $(p=0.354)$ & NR \\
\hline Shimizu et al. [20] & 2007 & Operated & 3 & $70 / 94$ & $\mathrm{NS}(p=0.738)$ & NR \\
\hline Tsai et al. [21] & 2007 & Operated & 1 & $97 / 58$ & NS $(p=0.150)$ & $S(p=0.004)$ \\
\hline Wang et al. [22] & 2007 & Operated & 3 & $514 / 409$ & NS $(p=0.312)$ & NR \\
\hline Bockhorn et al. [23] & 2008 & Operated & 4 & $101 / 101$ & $\operatorname{NS}(p=0.78)$ & $\operatorname{NS}(p=0.28)$ \\
\hline Hamady et al. [24] & 2008 & Operated & 4 & $138 / 46$ & NS $(p=0.6)$ & NR \\
\hline Vigano et al. [25] & 2008 & Operated & 1 & $55 / 66$ & $S(p=0.011)$ & NR \\
\hline Konopke et al. [26] & 2009 & Operated & 1 & $70 / 131$ & $S(p=0.030)$ & NR \\
\hline Ng et al. [27] & 2009 & Operated & 2 & $35 / 20$ & NS $(p=0.075)$ & $\mathrm{NS}(p=0.43)$ \\
\hline Xu et al. [28] & 2009 & Operated & 3 & $379 / 290$ & NS $(p>0.05)$ & NR \\
\hline Tonelli et al. [29] & 2010 & Operated & 1 & $70 / 37$ & $S(p=0.018)$ & NR \\
\hline Van der Pool et al. [30] & 2010 & Operated & 1 & 105/167 & NS $(p=0.6)$ & $\mathrm{NS}(p=0.3)$ \\
\hline Brouquet et al. [31] & 2011 & Operated & 1 & $47 / 13$ & $S(p=0.003)$ & NR \\
\hline Settmacher et al. [7] & 2011 & Operated & 1 & $158 / 224$ & $S(p=0.033)$ & $S(p=0.003)$ \\
\hline Swan et al. [32] & 2011 & Operated & 4 & $577 / 625$ & NS $(p=0.530)$ & NR \\
\hline Furukawa et al. [33] & 2012 & Unresectable & 1 & $26 / 14$ & $\mathrm{NS}(p=0.085)$ & NA \\
\hline Vigano et al. [34] & 2012 & Operated & 1 & 182/194 & NS & NR \\
\hline Dexiang et al. [35] & 2012 & All & 3 & $1061 / 552$ & $S(p<0.001)$ & NR \\
\hline Gur et al. [36] & 2013 & Operated & 1 & $79 / 79$ & NS $(p=0.14)$ & $\mathrm{S}(p=0.04)$ \\
\hline Nanji et al. [37] & 2013 & Operated & 1 & 125/195 & $S(p=0.003)$ & NS $(p=0.092)$ \\
\hline Ribeiro et al. [38] & 2012 & Operated & 3 & $89 / 81$ & $\mathrm{NS}(p=0.162)$ & $\mathrm{NS}(p=0.214)$ \\
\hline John et al. [39] & 2013 & Operated & 4 & $257 / 174$ & NS $(p=0.253)$ & NR \\
\hline Hackl et al. [3] & 2014 & All & 2 & 1019/407 & $\mathrm{NS}(p=0.799)$ & NR \\
\hline Kumar et al. [40] & 2014 & All & 1 & $1054 / 542$ & $S(p=0.003)$ & NR \\
\hline Kuo et al. [41] & 2015 & Operated & 2 & $104 / 55$ & $S(p=0.001)$ & NR \\
\hline Ali et al. [42] & 2015 & Operated & 3 & $66 / 50$ & NS $(p=0.997)$ & NR \\
\hline Kawamura et al. [43] & 2016 & Operated & 1 & $34 / 38$ & $S(p=0.010$ & NS \\
\hline Lemke et al. [44] & 2016 & Operated & 3 & $68 / 84$ & $\mathrm{~S}(p=\mathrm{NR})$ & NR \\
\hline Miller et al. [45] & 2017 & Operated & 3 & $181 / 46$ & $\mathrm{NS}(p=0.58)$ & NS $(p=0.87)$ \\
\hline Angelsen et al. [46] & 2017 & Operated & 4 & $39 / 488$ & NS $(p=0.068)$ & NR \\
\hline Bartolini et al. [47] & 2018 & Operated & 1 & $39 / 31$ & NS $(p=0.085)$ & $S(p=0.0001)$ \\
\hline Margonis et al. [48] & 2018 & Operated & 3 & $266 / 583$ & $S(p=0.02)$ & $\mathrm{NS}(p=0.58)$ \\
\hline Marques et al. [49] & 2018 & Operated & 3 & $95 / 55$ & NS $(p=0.505)$ & NS $(p=0.07)$ \\
\hline Memeo et al. [50] & 2018 & Operated & 4 & $753 / 1031$ & NS $(p=N R)$ & NR \\
\hline Quireze et al. [51] & 2018 & All & 3 & $38 / 16$ & $\mathrm{~S}(0.036)$ metachronous worse & NS $(p=0.629)$ \\
\hline Suthananthan et al. [52] & 2018 & All & 1 & $276 / 98$ & NS $(p=0.172)$ & NR \\
\hline Strandberg et al. [53] & 2018 & Operated & 1 & $146 / 138$ & $\mathrm{~S}(p=0.031)$ & NR \\
\hline Zhao et al. [54] & 2018 & Operated & 1 & $172 / 71$ & $\mathrm{NS}(p=0.110)$ & $\operatorname{NS}(p=0.088)$ \\
\hline
\end{tabular}

*Definition: 1, Time of primary tumour diagnosis/operation; 2, 3 months after primary tumour diagnosis/operation; 3, 6 months after primary tumour diagnosis/ operation; 4, 12 months after primary tumour diagnosis/operation. NA not applicable, NR not reported, $S$ significant, NS non-significant, OS overall survival, DFS disease-free survival 
Table 4 Summary of time points for defining synchronous vs. metachronous and prognostic significance as measured by OS and DFS in publications in 2005-2018

\begin{tabular}{llllll}
\hline Defining time point & Studies & Prognostic value & & \\
\cline { 3 - 6 } & $(n)$ & OS significant & OS non-significant & DFS significant & DFS non-significant \\
\hline Primary tumour diagnosis/surgery & 18 & 9 & 9 & 4 & 8 \\
Three months post-primary tumour diagnosis/surgery & 4 & 2 & 2 & 0 & 1 \\
Six months post-primary tumour diagnosis/surgery & 12 & 4 & 8 & 0 & 5 \\
Twelve months post-primary tumour diagnosis/surgery & 7 & 0 & 7 & 0 & 1 \\
Total & 41 & 15 & 26 & 4 & 15 \\
\hline
\end{tabular}

OS overall survival, DFS disease-free survival

study, a Cox regression analysis, including age, sex, tumour factors (tumour stage, nodal stage, right- vs. leftsided), number and size of liver metastases, time of detection (synchronous vs. metachronous), liver resection and the presence of lung metastases, was performed. In the multivariate analysis age, primary tumour origin (midgut vs. hindgut), size of largest liver metastasis and liver resection significantly predicted survival, while synchronous vs. metachronous (HR 0.91, 95\% CI 0.64-1.30) did not significantly influence survival [4]. In this article, patients that were operated and patients not operated for CRCLM were assessed separately. Ideally, additional treatment such as neoadjuvant, adjuvant and palliative chemotherapy therapy should have been controlled for in a multivariable analysis, but the rather small CRCLM cohort precludes further subgroup analysis.

Although the PRISMA statement guidelines were adhered for extraction of published data required for the study (definitions for and impact of synchronous vs. metachronous detection on prognosis at the different time points), a formal systematic review was not performed. A systematic review and meta-analysis to assess the prognostic value of synchronous vs. metachronous detection using the proposed definition is highly desirable, as this may clarify the impact on prognosis.

\section{Conclusion}

This study, to our knowledge, is the first to address the issue in a well-validated population-based cohort, and it fails to show any prognostic value in distinguishing synchronous from metachronous detection of CRCLM for any of the previously reported defining cut-off points, neither for operated patients nor for patients treated with palliative intent. We suggest using primary tumour diagnosis/operation as standard cut-off point to define synchronous/metachronous detection as a clinically relevant definition.

\section{Abbreviations}

CRC: Colorectal cancer; CRCLM: Colorectal cancer liver metastases; DFS: Disease-free survival; OS: Overall survival; SCRCR: Swedish Colorectal Cancer Registry
Acknowledgements

Not applicable.

\section{Authors' contributions}

The authors contributed equally in reviewing the clinical records. Data analysis was performed by JE, HN and EJ. EJ, JE, CS and JF performed the literature search. All authors read and approved the final manuscript.

\section{Funding}

None of the authors were supported by any grants or donations to complete this study. Open access funding provided by Karolinska Institute.

\section{Availability of data and materials}

The datasets generated and/or analyzed during the current study are not publicly available since it was not originally stated in the ethical application and subsequent approval.

Ethics approval and consent to participate

The study was approved by the Regional Ethical Review Board in Stockholm.

Consent for publication

Not applicable.

\section{Competing interests}

The authors declare that they have no competing interests.

\section{Author details}

${ }^{1}$ Division of Surgery, Department of Clinical Sciences, Karolinska Institutet, Danderyd Hospital, 18288 Stockholm, Sweden. ${ }^{2}$ Division of Surgery, Department of Clinical Science, Intervention and Technology (CLINTEC), Karolinska Institutet, Karolinska University Hospital, Stockholm, Sweden. ${ }^{3}$ Surgical Gastroenterology Unit, Department of Surgery, Groote Schuur Hospital, University of Cape Town Health Sciences Faculty, Cape Town, South Africa.

Received: 16 September 2019 Accepted: 16 December 2019

Published online: 26 December 2019

References

1. Ferlay J, Steliarova-Foucher E, Lortet-Tieulent J, Rosso S, Coebergh JW, Comber $\mathrm{H}$, et al. Cancer incidence and mortality patterns in Europe: estimates for 40 countries in 2012. Eur J Cancer. 2013;49(6):1374-403.

2. Sjovall A, Jarv $V$, Blomqvist $L$, Singnomklao T, Cedermark B, Glimelius B, et al. The potential for improved outcome in patients with hepatic metastases from colon cancer: a population-based study. Eur J Surg Oncol. 2004;30(8): 834-41

3. Hackl C, Neumann P, Gerken M, Loss M, Klinkhammer-Schalke M, Schlitt HJ. Treatment of colorectal liver metastases in Germany: a ten-year populationbased analysis of 5772 cases of primary colorectal adenocarcinoma. BMC Cancer. 2014;14:810.

4. Engstrand J, Nilsson H, Stromberg C, Jonas E, Freedman J. Colorectal cancer liver metastases - a population-based study on incidence, management and survival. BMC Cancer. 2018;18(1):78.

5. de Jong MC, Pulitano C, Ribero D, Strub J, Mentha G, Schulick RD, et al. Rates and patterns of recurrence following curative intent surgery for 
colorectal liver metastasis: an international multi-institutional analysis of 1669 patients. Ann Surg. 2009:250(3):440-8.

6. Pawlik TM, Schulick RD, Choti MA. Expanding criteria for resectability of colorectal liver metastases. Oncologist. 2008;13(1):51-64.

7. Settmacher U, Dittmar Y, Knosel T, Schone U, Heise M, Jandt K, et al. Predictors of long-term survival in patients with colorectal liver metastases: a single center study and review of the literature. Int J Color Dis. 2011;26(8):967-81.

8. Spelt L, Andersson B, Nilsson J, Andersson R. Prognostic models for outcome following liver resection for colorectal cancer metastases: a systematic review. Eur J Surg Oncol. 2012;38(1):16-24.

9. Adam R, de Gramont A, Figueras J, Kokudo N, Kunstlinger F, Loyer E, et al. Managing synchronous liver metastases from colorectal cancer: a multidisciplinary international consensus. Cancer Treat Rev. 2015;41(9):729-41.

10. Reddy SK, Barbas AS, Clary BM. Synchronous colorectal liver metastases: is it time to reconsider traditional paradigms of management? Ann Surg Oncol. 2009;16(9):2395-410

11. Schwarz RE, Berlin JD, Lenz HJ, Nordlinger B, Rubbia-Brandt L, Choti MA. Systemic cytotoxic and biological therapies of colorectal liver metastases: expert consensus statement. HPB (Oxford). 2013;15(2):106-15.

12. Jones RP, Malik HZ, Fenwick SW, Poston GJ. Perioperative chemotherapy for resectable colorectal liver metastases: where now? Eur J Surg Oncol. 2013; 39(8):807-11.

13. Brouquet A, Nordlinger B. Neoadjuvant therapy of colorectal liver metastases: lessons learned from clinical trials. J Surg Oncol. 2010;102(8): 932-6.

14. Kodeda K, Nathanaelsson L, Jung B, Olsson H, Jestin P, Sjovall A, et al. Population-based data from the Swedish Colon Cancer Registry. Br I Surg. 2013;100(8):1100-7.

15. Mclnnes MDF, Moher D, Thombs BD, McGrath TA, Bossuyt PM, Clifford T, et al. Preferred Reporting Items for a Systematic Review and Meta-analysis of Diagnostic Test Accuracy Studies: the PRISMA-DTA statement. JAMA. 2018;319(4):388-96.

16. Mutsaerts EL, van Ruth $\mathrm{S}$, Zoetmulder FA, Rutgers EJ, Hart AA, van Coevorden F. Prognostic factors and evaluation of surgical management of hepatic metastases from colorectal origin: a 10-year single-institute experience. J Gastrointest Surg. 2005;9(2):178-86.

17. Leporrier J, Maurel J, Chiche L, Bara S, Segol P, Launoy G. A populationbased study of the incidence, management and prognosis of hepatic metastases from colorectal cancer. Br J Surg. 2006;93(4):465-74.

18. Minagawa M, Yamamoto J, Miwa S, Sakamoto Y, Kokudo N, Kosuge T, et al. Selection criteria for simultaneous resection in patients with synchronous liver metastasis. Arch Surg. 2006;141(10):1006-12.

19. Taniai N, Yoshida H, Mamada Y, Matsumoto S, Mizuguchi Y, Suzuki H, et al. Outcome of surgical treatment of synchronous liver metastases from colorectal cancer. J Nippon Med School. 2006;73(2):82-8.

20. Shimizu Y, Yasui K, Sano T, Hirai T, Kanemitsu Y, Komori K, et al. Treatment strategy for synchronous metastases of colorectal cancer: is hepatic resection after an observation interval appropriate? Langenbeck's Arch Surg. 2007:392(5):535-8.

21. Tsai MS, Su YH, Ho MC, Liang JT, Chen TP, Lai HS, et al. Clinicopathological features and prognosis in resectable synchronous and metachronous colorectal liver metastasis. Ann Surg Oncol. 2007;14(2):786-94.

22. Wang X, Hershman DL, Abrams JA, Feingold D, Grann VR, Jacobson JS, et al. Predictors of survival after hepatic resection among patients with colorectal liver metastasis. Br J Cancer. 2007:97(12):1606-12.

23. Bockhorn M, Frilling A, Fruhauf NR, Neuhaus J, Molmenti E, Trarbach T, et al. Survival of patients with synchronous and metachronous colorectal liver metastases - is there a difference? J Gastrointest Surg. 2008;12(8):1399-405.

24. Hamady ZZR, Malik HZ, Alwan N, Wyatt JI, Prasad RK, Toogood GT, et al. Surgeon's awareness of the synchronous liver metastases during colorectal cancer resection may affect outcome. Eur J Surg Oncol. 2008;34(2):180-4.

25. Vigano L, Ferrero A, Lo Tesoriere R, Capussotti L. Liver surgery for colorectal metastases: results after 10 years of follow-up. Long-term sunvivors, late recurrences, and prognostic role of morbidity. Ann Surg Oncol. 2008;15(9):2458-64.

26. Konopke R, Kersting S, Distler M, Dietrich J, Gastmeier J, Heller A, et al. Prognostic factors and evaluation of a clinical score for predicting survival after resection of colorectal liver metastases. Liver Int. 2009;29(1):89-102.

27. Ng WWC, Cheung YS, Wong J, Lee KF, Lai PBS. A preliminary analysis of combined liver resection with new chemotherapy for synchronous and metachronous colorectal liver metastasis. Asian Journal of Surgery. 2009; 32(4):189-97.
28. Xu J, Wei Y, Zhong Y, Fan J, Zhou J, Qin L, et al. Hepatectomy for liver metastasis of colorectal cancer. Int J Color Dis. 2009;24(4):419-25.

29. Tonelli F, Leo F, Nobili S, Mini E, Batignani G. Prognostic factors in primary and iterative surgery of colorectal liver metastases. J Chemother. 2010;22(5): $358-63$.

30. van der Pool AEM, Lalmahomed ZS, Ozbay Y, de Wilt JHW, Eggermont AMM, Jzermans JNM, et al. 'Staged' liver resection in synchronous and metachronous colorectal hepatic metastases: differences in clinicopathological features and outcome. Color Dis. 2010;12(10):e229-e35.

31. Brouquet A, Overman MJ, Kopetz S, Maru DM, Loyer EM, Andreou A, et al. Is resection of colorectal liver metastases after a second-line chemotherapy regimen justified? Cancer. 2011;117(19):4484-92.

32. Swan PJ, Welsh FK, Chandrakumaran K, Rees M. Long-term survival following delayed presentation and resection of colorectal liver metastases. Br J Surg. 2011;98(9):1309-17.

33. Furukawa K, Shiba H, Haruki K, Fujiwara Y, lida T, Mitsuyama Y, et al. The Glasgow prognostic score is valuable for colorectal cancer with both synchronous and metachronous unresectable liver metastases. Oncol Lett. 2012;4(2):324-8.

34. Vigano L, Russolillo N, Ferrero A, Langella S, Sperti E, Capussotti L. Evolution of long-term outcome of liver resection for colorectal metastases: analysis of actual 5-year survival rates over two decades. Ann Surg Oncol. 2012;19(6): 2035-44.

35. Dexiang Z, Li R, Ye W, Haifu W, Yunshi Z, Qinghai Y, et al. Outcome of patients with colorectal liver metastasis: analysis of 1,613 consecutive cases. Ann Surg Oncol. 2012;19(9):2860-8.

36. Gur I, Diggs BS, Wagner JA, Vaccaro GM, Lopez CD, Sheppard BC, et al. Safety and outcomes following resection of colorectal liver metastases in the era of current perioperative chemotherapy. J Gastrointest Surg. 2013; 17(12):2133-42.

37. Nanji S, Cleary S, Ryan P, Guindi M, Selvarajah S, Grieg P, et al. Up-front hepatic resection for metastatic colorectal cancer results in favorable longterm survival. Ann Surg Oncol. 2013;20(1):295-304.

38. Ribeiro HS, Stevanato-Filho PR, Costa WL Jr, Diniz AL, Herman P, Coimbra FJ. Prognostic factors for survival in patients with colorectal liver metastases: experience of a single brazilian cancer center. Arq Gastroenterol. 2012;49(4):266-72.

39. John SK, Robinson SM, Rehman S, Harrison B, Vallance A, French JJ, et al. Prognostic factors and survival after resection of colorectal liver metastasis in the era of preoperative chemotherapy: an 11-year single-centre study. Dig Surg. 2013;30(4-6):293-301.

40. Kumar R, Price TJ, Beeke C, Jain K, Patel G, Padbury R, et al. Colorectal cancer survival: an analysis of patients with metastatic disease synchronous and metachronous with the primary tumor. Clin Colorectal Cancer. 2014; 13(2):87-93.

41. Kuo IM, Huang SF, Chiang JM, Yeh CY, Chan KM, Chen JS, et al. Clinical features and prognosis in hepatectomy for colorectal cancer with centrally located liver metastasis. World J Surg Oncol. 2015;13:92.

42. Ali MA, Di Sandro S, Lauterio A, Concone G, Mangoni I, Ferla F, et al. Repeat hepatectomy for recurrent colorectal liver metastases: is it worth the challenge? J Gastrointest Surg. 2015;19(12):2192-8.

43. Kawamura J, Yazawa T, Sumida K, Kida Y, Ogawa R, Tani M, et al. Clinical efficacy of liver resection after downsizing systemic chemotherapy for initially unresectable liver metastases. World J Surg Oncol. 2016;14(1). https://doi.org/10.1186/s12957-016-0807-7.

44. Lemke J, Cammerer G, Ganser J, Scheele J, Xu P, Sander S, et al. Survival and prognostic factors of colorectal liver metastases after surgical and nonsurgical treatment. Clin Colorectal Cancer. 2016;15(4):e183-e92.

45. Miller CL, Taylor MS, Qadan M, Deshpande V, Worthington S, Smalley R, et al. Prognostic significance of surgical margin size after neoadjuvant FOLFOX and/or FOLFIRI for colorectal liver metastases. J Gastrointest Surg. 2017:21(11):1831-40.

46. Angelsen JH, Horn A, Sorbye H, Eide GE, Løes IM, Viste A. Population-based study on resection rates and survival in patients with colorectal liver metastasis in Norway. Br J Surg. 2017;104(5):580-9.

47. Bartolini I, Ringressi MN, Melli F, Risaliti M, Brugia M, Mini E, et al. Analysis of prognostic factors for resected synchronous and metachronous liver metastases from colorectal cancer. Gastroenterol Res Pract. 2018;2018.

48. Margonis GA, Buettner S, Andreatos N, Kim Y, Wagner D, Sasaki K, et al. Association of BRAF mutations with survival and recurrence in surgically treated patients with metastatic colorectal liver cancer. JAMA Surg. 2018; 153(7):e180996. 
49. Marques MC, CR HS, Costa WL Jr, VHF d J, de Macedo MP, Diniz AL, et al. Is primary sidedness a prognostic factor in patients with resected colon cancer liver metastases (CLM)? J Surg Oncol. 2018;117(5):858-63.

50. Memeo R, de Blasi V, Adam R, Goéré D, Piardi T, Lermite E, et al. Margin status is still an important prognostic factor in hepatectomies for colorectal liver metastases: a propensity score matching analysis. World J Surg. 2018; 42(3):892-901.

51. Quireze Junior C, Brasil AMS, Morais LK, Campion ERL, Taveira EJF, Rassi MC. Metachronous colorectal liver metastases has better prognosis - is it true? Arq Gastroenterol. 2018;55(3):258-63.

52. Suthananthan $A E$, Bhandari $M$, Platell C. Influence of primary site on metastatic distribution and survival in stage IV colorectal cancer. ANZ J Surg. 2018;88(5):445-9.

53. Strandberg Holka P, Eriksson S, Eberhard J, Bergenfeldt M, Lindell G, Sturesson C. Significance of poor performance status after resection of colorectal liver metastases. World J Surg Oncol. 2018;16(1):3.

54. Zhao Y, Deng Y, Peng J, Sui Q, Lin J, Qiu M, et al. Does the preoperative prognostic nutritional index predict survival in patients with liver metastases from colorectal cancer who underwent curative resection? J Cancer. 2018; 9(12):2167-74.

55. Veereman G, Robays J, Verleye L, Leroy R, Rolfo C, Van Cutsem E, et al. Pooled analysis of the surgical treatment for colorectal cancer liver metastases. Crit Rev Oncol Hematol. 2015;94(1):122-35.

56. Lam WW, Laurence JM, Pang T, Johnston E, Hollands MJ, Pleass HC, et al. A systematic review of a liver-first approach in patients with colorectal cancer and synchronous colorectal liver metastases. HPB. 2014;16(2):101-8.

57. Siriwardena AK, Mason JM, Mullamitha S, Hancock HC, Jegatheeswaran S. Management of colorectal cancer presenting with synchronous liver metastases. Nat Rev Clin Oncol. 2014;11(8):446-59.

58. Slesser AA, Simillis C, Goldin R, Brown G, Mudan S, Tekkis PP. A metaanalysis comparing simultaneous versus delayed resections in patients with synchronous colorectal liver metastases. Surg Oncol. 2013;22(1):36-47.

59. Van den Eynden GG, Majeed AW, Illemann M, Vermeulen PB, Bird NC, Hoyer-Hansen $G$, et al. The multifaceted role of the microenvironment in liver metastasis: biology and clinical implications. Cancer Res. 2013;73(7): 2031-43.

60. Hagness M, Foss A, Egge TS, Dueland S. Patterns of recurrence after liver transplantation for nonresectable liver metastases from colorectal cancer. Ann Surg Oncol. 2014;21(4):1323-9.

61. Hagness M, Foss A, Line PD, Scholz T, Jorgensen PF, Fosby B, et al. Liver transplantation for nonresectable liver metastases from colorectal cancer. Ann Surg. 2013;257(5):800-6.

62. Kartalis N, Brismar TB, Mihocsa L, Isaksson B, Albiin N. The added value of contrast-enhanced ultrasound in patients with colorectal cancer undergoing preoperative evaluation with extensive gadobenate dimeglumine liver MRI. Eur Radiol. 2011;21(10):2067-73.

63. Zech CJ, Korpraphong P, Huppertz A, Denecke T, Kim MJ, Tanomkiat W, et al. Randomized multicentre trial of gadoxetic acid-enhanced MRI versus conventional MRI or CT in the staging of colorectal cancer liver metastases. Br J Surg. 2014;101(6):613-21.

64. Zech CJ, Justo N, Lang A, Ba-Ssalamah A, Kim MJ, Rinde H, et al. Cost evaluation of gadoxetic acid-enhanced magnetic resonance imaging in the diagnosis of colorectal-cancer metastasis in the liver: results from the VALUE Trial. Eur Radiol. 2016;26(11):4121-30.

65. Zech CJ, Grazioli L, Jonas E, Ekman M, Niebecker R, Gschwend S, et al. Health-economic evaluation of three imaging strategies in patients with suspected colorectal liver metastases: Gd-EOB-DTPA-enhanced MRI vs. extracellular contrast media-enhanced MRI and 3-phase MDCT in Germany, Italy and Sweden. Eur Radiol. 2009;19 Suppl 3:S753-S763.

\section{Publisher's Note}

Springer Nature remains neutral with regard to jurisdictional claims in published maps and institutional affiliations.

Ready to submit your research? Choose BMC and benefit from:

- fast, convenient online submission

- thorough peer review by experienced researchers in your field

- rapid publication on acceptance

- support for research data, including large and complex data types

- gold Open Access which fosters wider collaboration and increased citations

- maximum visibility for your research: over $100 \mathrm{M}$ website views per year

At BMC, research is always in progress.

Learn more biomedcentral.com/submissions 